\section{The Nutrition Society}

THE science of nutrition expanded so much of recent years that it was no longer adequately covered by existing societies. In July 1941, therefore, a proposal to form a nutrition society was put forward, under the auspices of the heads of various well. known institutes engaged in research on nutrition in Britain, which would follow on the lines of the Physiological and Biochemical Societies, although there was no question of publishing a journal at that time. At the first meeting in the same month, it was felt that the main object of the new Society should be to form a common meeting place for workers in the various fields of nutrition, namely, physiological, biochemical, agricultural, medical, sociological, economic and public health, and that it would be useful during the War to have a separate Scottish Group. The Society had not long been founded when it became apparent that the value of its proceedings would be enhanced by their reaching an audience wider than that which actually participated in its meetings. The Royal College of Physicians, impressed with the advantage which the medical profession might reap from gaining immediate access to the records of the meetings of the Society, made an offer which enabled the financial and other difficulties standing in the way of publication during war-time to be overcome. Accounts of the first meoting and of English and Scottish Group meetings up to May 30, 1942, are now published (Proc. Nutrition Soc., 1, Nos. 1 and 2, 1-112; 1944) and include "Evaluation of Nutritional States ; Food Production, Distribution and Supplies in Relation to Human Needs", and "Problems of Collective Feeding in War Time". The second double number will contain reports of meetings on dehydration, food supplies, trace elements and diet in pregnancy and lactation.

\section{British Medicine and the Göttingen Medical School}

IN a recent paper (Bull. Hist. Med., 14, 449 ; 1943) Prof. Max Neuburger remarks that during the eighteenth century inadequate facilities for teaching and research prevented most of the medical schools in Germany from furthering either medical training or scientific research. On the other hand, the medical school at Vienna and the Medical Faculty at Göttingen were remarkable exceptions, and owed their celebrity to two famous pupils of Boerhaave, namely, Gerhard van Swieten at Vienna and Albrecht v. Haller at Göttingen. George II, who founded the University of Göttingen in 1734, invited Haller to fill the vacant chair of medicine, which included anatomy, surgery and botany. Haller had previously spent some time in London, where he made the acquaintance of several English physicians and surgeons such as Sir Hans Sloane, John Pringle and William Cheselden, and frequently quoted British writers, notably Stephen Hales, John Mayow and Thomas Willis, in his own works. During the seventeen years when he resided at Göttingen, he exercised a great influence on the University, being responsible for the erection of an anatomical theatre, a botanical garden and a lying-in institution. He also founded a scientific society of which he was the first and permanent president, and a scientific journal to which he made more than a thousand contributions. Between 1739 and 1744 he completed the six-volume edition of Boerharve's "Institutiones", for which he was elected a foreign member of the Royal Society. $\mathrm{He}$ was also author of numerous other works on anatomy, physiology, medicine, surgery and botany. In 1739 he was appointed physician in ordinary to George II, who conferred a knighthood upon him and made him one of his consultant physicians. Owing to reasons of health, he left Göttingen for Berne in 1753. Many of Haller's successors at Gött. ingen, as Prof. Neuburger points out, had studied in London. Among them may be mentioned Roederer, Sömmering, Thomas Young and Blumenbach.

\section{Quekett Microscopical Club}

For some eighty years, the Quekett Microscopical Club has taken a leading part in the development of microscopy, and many leading research workers have been included on its membership roll and have recorded the results of their work in its journal. Thanks to the courtesy of the Royal Society, the Club, which at present has a membership of nearly three hundred and fifty, is now meeting at Burlington House, Piccadilly, where the Club's library and slide cabinet are again available, after having been removed to safety in the country during the last four years. Meetings are held as originally, on the second and fourth Tuesday in each month, the earlier being an ordinary (lecture) meeting, whereas the latter is devoted to the exhibition of specimens, apparatus and general discussion. On Saturday afternoons, collecting excursions are conducted and visits to places of interest to microscopists are arranged. The affairs of the Club are managed by two secretaries: Mr. E. P. Herlihy, 76 Brook Green, London, W.6, dealing with business matters, and Dr. James David. son, 41 Brampton Grove, London, N.W.4, with scientific matters and papers.

\section{Chagas's Disease in Brazil}

IN a recent paper (Bol. Of. San. Panamericana, 22, 773 ; 1943), C. Chagas, jun., states that during the thirty-three years since Chagas's disease was discovered in a small area in the State of Minas Gerais, Brazil, the disease has been found to have spread throughout North and South Amorica. As regards the parasitology, it is now universally accepted that Schizotrypanum is the cause of the disease. Studies are now being made to obtain more complete data regarding insect vectors, prevalence of the disease and animal carriers of the virus. Among domestic animals, cats and dogs take the first place as carriers.

\section{Work at the Madrid Observatory}

Butuerin 9 from the Madrid Observatory deals first of all with the photographic and visual observations of Novi Lacertæ 1936, made at the Observatory. The photographs were obtained by means of a camera of short focus used in conjunction with the Grubb photographic equatorial, which has an aperture of $16 \mathrm{~cm}$. and focal length $80 \mathrm{~cm}$. The method employed for determining the magnitude of the nova was by measuring the diameters of the focal images, and applying the formulæ of Charlier and Parkhurst, adopting the mean from both formulo. Nine comparison stars of various spectral types were used and the results are shown in Table 2 , the observations extending over the period June 21-July 17, 1936. In addition to the photographic observations, about 500 visual observations were made between June 18 and July 20, the results of which are given in Table 3, and from these the colour-index was deduced. This varied according to the spectral type of comparison star; for Class $F 0$ it was $0 \cdot 30$ and for Class $B 8$ it 
was $-0 \cdot 08$, and was practically zero for Class $A 0$. A curve shows the results of the photographic and visual determinations of magnitudes, the photographic magnitudes being represented by circles which lie close to the visual magnitude curve.

Similar work was done with Nova Herculis 1934, the observations extending from December 16, 1934, to April 30, 1935, and the light curve of the nova between these dates is given, circles representing the photographic magnitudes as in the case of Nova Lacertæ. A maximum difference occurred about the middle of January, this difference (photographicvisual) being 0.5 mag. It was found impossible to deduce the value of the colour-index, but it is hoped that this will be done when further data are available from various scientific journals, thus enabling comparisons to be made with the work at the Observatory of Madrid.

Bulletin 10 from the Observatory deals chiefly with solar prominences observed at the University of Valencia during 1938 , and is a continuation of the 1937 observations recorded in a previous issue of the bulletin (see NATURE, 151, $405 ; 1943$ ). In addition to a description of the solar spots observed in 1938, the issue contains the positions of Comets van Gent, Whipple-Bernasconi-Kulin and Whipple-Fedtke, determined from photographic observations.

\section{Aeroplane Compass}

IN Sky and Telescope of January 1944 there is a description of the Gyro Flux Gate Compass System, which has overcome many difficulties for air navigators. It combines the action of the flux of the earth's magnetic field with a gyroscope designed to keep it horizontal in spite of the movements of the aeroplane. It is very much more sensitive than the ordinary compass, and it can be operated close to the earth's magnetic poles, if necessary. The existence of the instrument has been revealed recently, because it is believed that some of the compasses have fallen into the hands of the enemy, though it seems certain that he cannot produce it in great quantity during the present War. A description of the instrument is given; but the technical details are too complicated to be dealt with here. Its practical utility can be judged from the fact that its reading of true compass directions and its reliability under varying conditions have contributed to reduce the number of accidents due to uncertainties in navigation.

\section{Transmission Line Supports}

IN a paper on reinforced concrete supports read recently in London by Messrs. E. C. Neate and W. F. Bowling before the Institution of Electrical Engineers, consideration is first given to previous work done in Great Britain, and this is followed by a discussion of the requirements of a reinforced-concrete transmission-line pole. Details of experimental poles are given with an analysis of the results of tests to destruction. A graphical method of design is developed, and sufficient information is provided to enable future work to be undertaken on the bases established. An expression is obtained for the deflexion of a pole under load, and it is shown that deflexion cannot be taken as a criterion for proof-test purposes. The authors discuss fabrication and erection methods, and the paper concludes with a survey of the advantages and disadvantages of the concrete pole, reference being made to a questionnaire issued to a number of users in Great Britain.
St. Louis Chapter of the Society of the Sigma Xi

THE St. Louis Chapter of the Society of the Sigma $\mathrm{X}$ i was installed at St. Louis University on March 16 by Prof. Harlow Shapley and Prof. George A. Baitsell. Forty members and three associate members formed the petitioning group. Prof. Shapley spoke on "Co-operation in Research", and later, Prof. Peter Debye gave the Sigma Xi Lecture, "The Magnetic Approach to Absolute Zero". Chaptery officers elected for the following year were Kermit Christensen (president), Charles H. Neilson (vice-president), Arthur G. Rouse (secretary) and Alfred H. Weber (treasurer).

\section{Announcements}

THE Albert Gold Medal of the Royal Society of Arts has been awarded to Sir Henry Tizard, president of Magdalen College, Oxford, and formerly rector of the Imperial College of Science and Technology, distinguished for his scientific work in the development of aircraft (see Nature, Aug. 1, 1942, p. 148).

THe first award of a gold medal founded in memory of Dr. Bimala Churn Law by the Indian Association for the Cultivation of Science has been made to Sir Henry Dale, president of the Royal Society. The award is given for important contributions to science including medicine.

Prof. JoHn MacMurray, Grote professor of the philosophy of mind and logic in the University of London, has been appointed professor of moral philosophy in the University of Edinburgh in succession to Prof. A. E. Taylor.

DR. S. W. WOOLDRIDGE, reader in geography in the University of London (King's College), has been appointed to the chair of geography in the University tenable at Birkkeck College, in succession to Prof. E. G. R. Taylor.

AT the anniversary meeting of the Linnean Society of London held on May 24 the president, Mr. A. D. Cotton, delivered a presidential address, "The Megaphytic Habit in the African Tree Senecios and other Genera". The following were elected officers for the year 1944-45: President, Mr. A. D. Cotton; Treasurer, Colonel F. C. Stern; Deputy Treasurer, Dr. B. Barnes ; Secretaries, Dr. B. Barnes (botany) and Dr. Malcolm A. Smith (zoology); Members of Council, Prof. A. J. E. Cave, Captain Cyril Diver, Dr. Edward Hindle, Mr. A. A. Pearson, Lieut.-Colonel R. B. Seymour Sewell.

LORD KEMSLEy has made a gift to the University of Sheffield to provide, during a period of seven years from its first coming into operation, an annual travelling fellowship of $£ 400$ a year. The fellowship will come into operation as soon as circumstances allow its conditions to be fulfilled. Candidates must be unmarried men and British subjects by birth holding the degree of bachelor of the University of Sheffield and who since graduation have not taken up other full-time work than study or research in a university in the United Kingdom. The main condition of tenure is that the Fellow shall actively study at first hand the ways of a good life and of thought in the country selected, and shall become efficient in speaking and reading its language. Candidates will generally be selected from the Faculty of Arts. No applications will be accepted before a date to be announced in due course by the University of Sheffield. 